\title{
Emergency Presentation of Corneal Graft Patients
}

\author{
ROBERT J. MORRIS and COLIN M. KIRKNESS \\ London
}

\begin{abstract}
Summary
One hundred and forty-two patients with corneal grafts made 205 visits to the Accident and Emergency Department of Moorfields Eye Hospital during a twelvemonth period. One-third of cases showed a graft rejection episode while another third had a problem directly related to the graft. The figures emphasise the need for continuing patient education so that graft problems may be dealt with promptly.
\end{abstract}

In the last 40 years, since the development of microsurgical techniques and the introduction of steroids, corneal graft surgery has become a widely practised technique with high success rates in favourable cases. The total number of grafts performed in the United Kingdom is unknown, but there are now more than 120 centres engaged in corneal transplantation. ${ }^{1}$ At Moorfields Eye Hospital, over 300 grafts are performed annually. With demand and waiting lists for corneas growing faster than for any other organ, ${ }^{1}$ improved techniques available for corneal storage and the increasing role of Eye Banks in the provision of corneas, the number of corneal transplantations being performed can be expected to increase even more. In the United States, the numbers have increased from $2,000 /$ year in $1973^{2}$ to $30,000 /$ year in $1985 .^{3}$

Although the majority of keratoplasties are successful, some patients, particularly those at high risk, might be expected to develop problems in the post-operative period. Allograft rejection is a leading cause of failure of corneal grafts, ${ }^{4}$ but other conditions may arise which can jeopardise both the graft and the vision. In order to evaluate these problems, we set up a prospective study of corneal graft patients presenting as emergencies to our Accident and Emergency Department.

\section{Patients and Methods}

Included in this study were consecutive patients who had undergone either penetrating or lamellar keratoplasty and who presented for emergency treatment to the Accident and Emergency Department of Moorfields Eye Hospital, City Road, during the twelve-month period from April 1986 to March 1987.

Each patient was questioned about duration of symptoms, present therapy, or any recent change in therapy. The details of graft surgery and indications for surgery were available from patient records. Clinical assessment was performed by both the casualty registrar as well as a member of the corneal unit responsible for the patient's long term care. Where appropriate, investigations were performed to confirm the clinical diagnosis.

Corneal graft rejection was diagnosed in patients with one or more of the following criteria: circumlimbal flush, cells or flare in the anterior chamber, keratitic precipitates, epithelial or endothelial rejection lines or sudden graft oedema in a previously quiet eye. Difficulty can arise in distinguishing patients with recurrent stromal herpetic keratitis from those with graft rejection, but the former was diagnosed if the keratitic precipitates and oedema occurred on to the host cornea, other- 


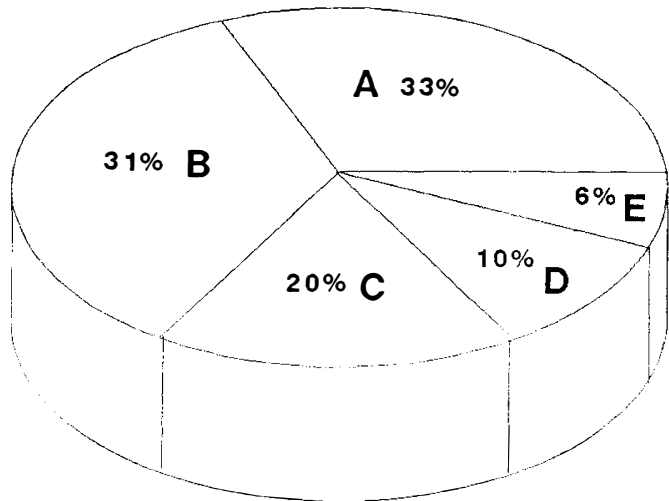

Fig. 1. Pie chart showing the relative frequency of diagnostic categories. 100 per cent $=205$ patient visits. A-non-graft-related problems; B-graft rejections; $C-$ graft-related problems; D-nil abnormal diagnosed; E-problems in longstanding decompensated grafts.

wise the patient was considered to have a graft rejection.

\section{Results}

A total of 142 patients were included in the study, 111 presenting on a single occasion, 18 twice, 7 three times, 2 four times, 2 five times, one eight times and one on eleven occasions. This totalled 205 patient visits in all.

Five main groups of patients were considered (Fig. 1):

A. Patients with corneal graft rejection.

B. Patients with conditions directly related to their corneal graft.

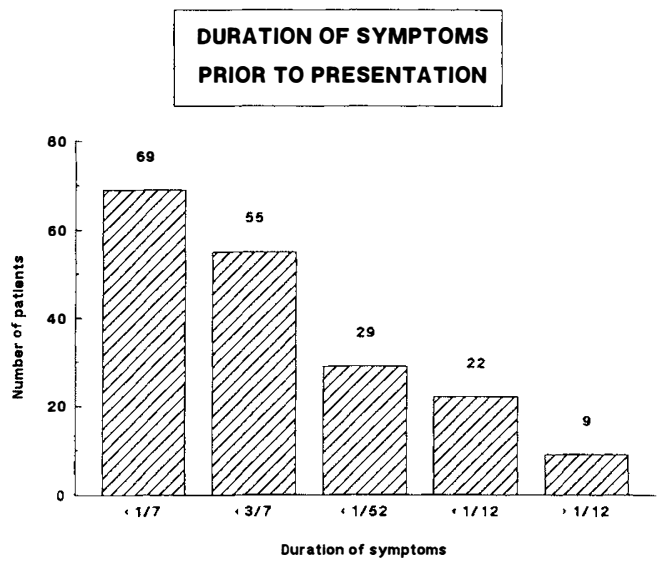

Fig. 2. Histogram showing time of presentation after onset of symptoms.
C. Patients with conditions unrelated to corneal graft surgery.

D. Patients with long-standing graft decompensation.

E. Patients in whom no abnormality was detected to account for their symptoms.

Duration of Symptoms Prior to Presentation Most patients attended soon after the onset of their symptoms, but with some there was a significant delay prior to presentation (Fig. 2). Several of those who delayed had had surgery many years previously and were unaware of their continuing vulnerability to complications. Conversely, those presenting early tended to be well informed and highly motivated. In others, however, attendance was delayed following presentation to, and treatment by, other medical practitioners not concerned directly with the management of the corneal graft.

\section{Corneal Graft Rejections}

Sixty-five (55 patients) episodes of corneal graft rejection were seen. Of these, 45 per cent had had a recent reduction or cessation of topical steroid therapy in the 3 months prior to presentation (Fig. 3). The interval between surgery and the onset of graft rejection is shown in Figure 4.

One case of epithelial rejection was seen 18 months after penetrating keratoplasty and one case of lamellar keratoplasty developed an acute rejection within 2 months of surgery

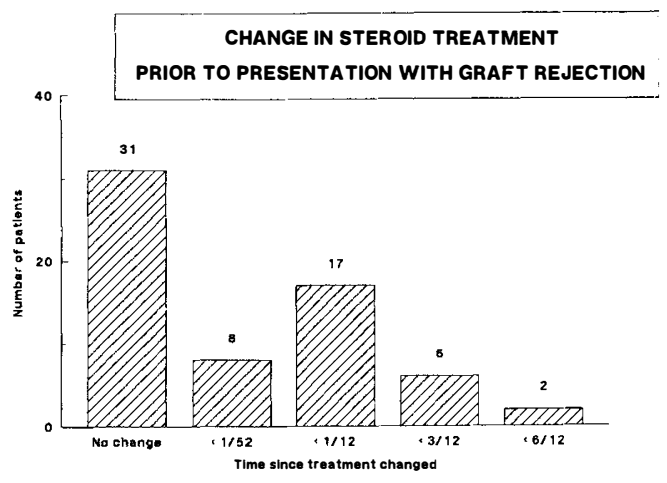

Fig. 3. Histogram showing number of patients with recent change in steroid therapy who developed graft rejection episodes. 


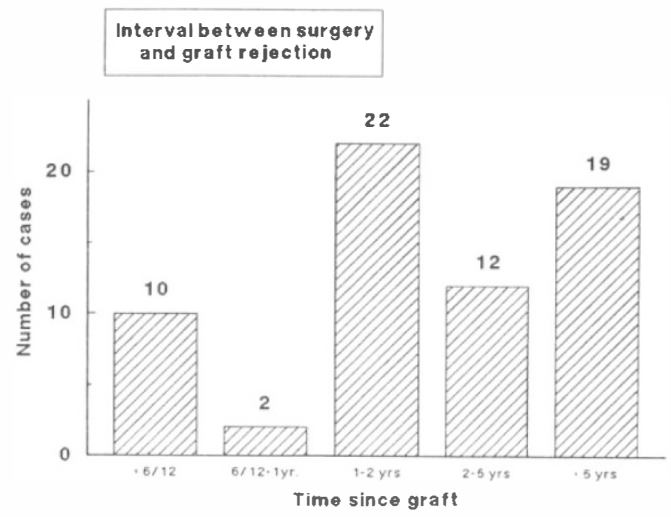

Fig. 4. Histogram showing interval between surgery and graft rejection.

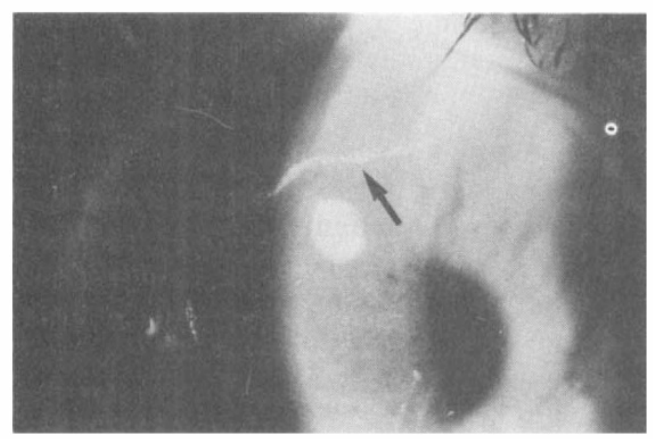

Fig. 5. A lamellar graft showing epithelial rejection line (arrow).

(Fig. 5). All other cases showed endothelial rejection reactions. Two cases of rejection were associated with vascularisation along loose sutures and are included in the category of graft rejection rather than under graft related conditions. In the 4 cases who did not present for over a month, three developed endothelial decompensation and one vascularisation of the surperior third of the cornea.

\section{Graft Related Conditions}

Forty-two cases (38 patients) were seen in which the diagnosis was a condition directly related to the corneal graft (Table I). The most common problem being suture related, of which 9 had loose sutures (Fig. 6), 8 broken sutures, 2 epithelial defects overlying sutures and one mucus attached to a suture. Of the 7 patients with recurrent herpes simplex keratitis, all had stromal disease and no case of recurrent epithelial herpes was seen. Four cases of corneal bacterial infection were seen, one case of pseudomonas endophthalmitis occurring in the first 2 weeks after surgery, and 3 patients developed corneal abscesses, one of which was related to a broken suture. Included in the category of post-operative complications were one patient with cystoid macula oedema, two with post-operative inflammation, as a result of difficulty instilling their steroid drops on discharge from hospital, and 2 patients with transient increase in intraocular pressure. One patient with StevensJohnson syndrome developed a corneal melt in May 1986 which required re-grafting and in March 1987 he subsequently developed a corneal perforation.

The interval between surgery and the onset of symptoms is shown in Figure 7.

\section{Non-Graft-related conditions}

Sixty-six cases (50 patients) were seen in

Table I. The frequency of graft-related problems with breakdown into sub groups

\begin{tabular}{|c|c|c|c|}
\hline SUTURE RELATED & (20) & POST-OPERATIVE COMPLICATIONS & $(5)$ \\
\hline Loose sutures & 9 & Post-operative inflammation & 2 \\
\hline Broken sutures & 8 & Transient rise in intraocular pressure & 2 \\
\hline Epithelial defects & 2 & Cystoid macula oedema & 1 \\
\hline Mucus attached to suture & 1 & EPITHELIAL DISTURBANCE & (4) \\
\hline RECURRENT HERPES & (7) & \multirow{4}{*}{ CORNEAL MELT/PERFORATION } & \\
\hline INFECTION & (4) & & \multirow[t]{3}{*}{ (2) } \\
\hline Corneal abscess & 3 & & \\
\hline Endophthalmitis & 1 & & \\
\hline
\end{tabular}




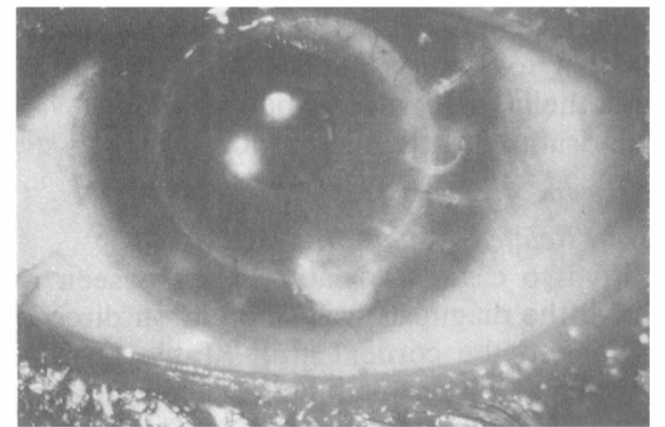

Fig. 6. A running suture which has broken, loosened, collected mucus and attracted new vessels.

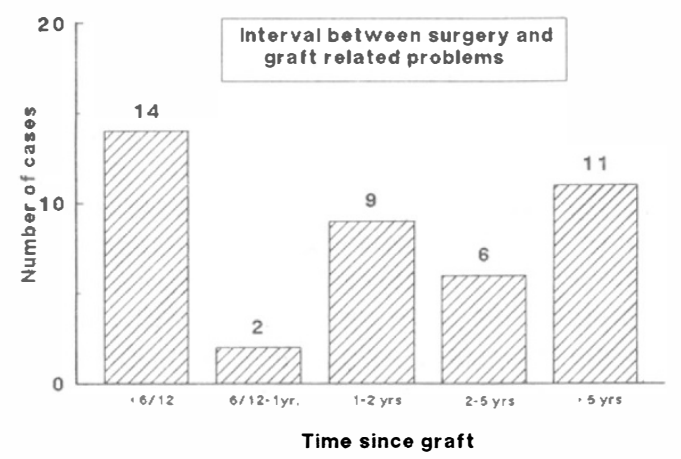

Fig. 7. Histogram showing interval between surgery and graft related problems. which the diagnosis was not directly related to the corneal graft (Table II, Figs 8 and 9). The most common in the group of non-graftrelated conditions was staphyloccal lid disease producing symptoms of itching, grittiness, burning and redness. We saw no corneal complications related to this.

Subconjunctival haemorrhage was also common, the patients all presenting early. Five cases of viral conjunctivitis were seen and two of staphyloccal conjunctivitis.

\section{Decompensated Grafts}

Thirteen cases of patients with chronically decompensated grafts which had resulted in either corneal oedema or in some cases vascularisation were seen (Table III). One patient, wearing a cosmetic shell over a phthisical eye, developed giant pupillary conjunctivitis.

\section{No Abnormality}

Twenty cases (17 patients) were in this group of which over 50 per cent had had a recent graft rejection episode. Patients tended to present earlier than in other groups -75 per cent presenting within 3 days of the onset of symptoms.

Table II. The diagnoses seen in problems which were not directly graft related

\begin{tabular}{|c|c|c|c|}
\hline LID MARGIN DISEASE & (21) & GLAUCOMA RELATED & (4) \\
\hline Staphyloccal lid disease & 20 & Blocked silicone tube & 3 \\
\hline Chalazion & 1 & Inflammed bleb & 1 \\
\hline CONJUNCTIVITIS & (7) & TRAUMA & (4) \\
\hline Viral & 5 & Corneal abrasion & 4 \\
\hline Bacterial & 2 & MISCELLANEOUS & (8) \\
\hline \multicolumn{2}{|c|}{ SUB-CONJUNCTIVAL HAEMORRHAGE (8) } & Episcleritis & 2 \\
\hline CONTACT LENS RELATED & (5) & $\begin{array}{l}\text { Trichiasis } \\
\text { Cataract }\end{array}$ & $\begin{array}{l}2 \\
1\end{array}$ \\
\hline \multirow{2}{*}{$\begin{array}{l}\text { Contact lens induced abrasion } \\
\text { Scratched contact lenses }\end{array}$} & \multirow{2}{*}{$\begin{array}{l}3 \\
2\end{array}$} & Poor corneal wetting & 1 \\
\hline & & $\begin{array}{l}\text { Corneal exposure } \\
\text { Uveitis }\end{array}$ & $\begin{array}{l}1 \\
1\end{array}$ \\
\hline ALLERGY/TOXICITY & (5) & NON-OPHTHALMOLOGICAL & (4) \\
\hline Thiomersal sensitivity & 1 & Maxillary sinusitis & 1 \\
\hline $\begin{array}{l}\text { Preservative toxicity } \\
F_{3} T \text { toxicity }\end{array}$ & $\begin{array}{l}2 \\
1\end{array}$ & Trigeminal neuralgia & 1 \\
\hline Chloramphenicol allergy & 1 & Sebaceous cyst & 1 \\
\hline & & Bee sting & \\
\hline
\end{tabular}




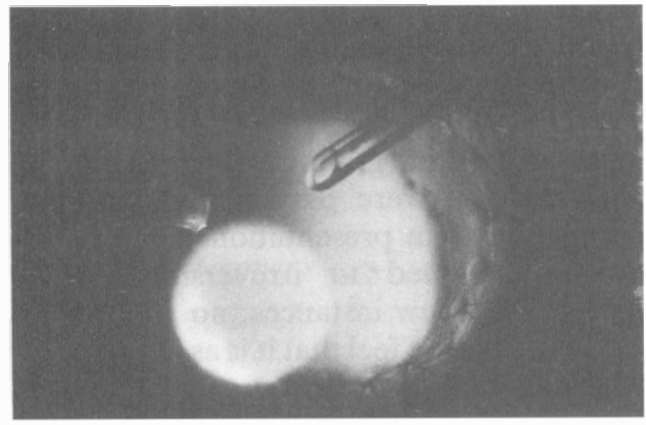

Fig. 8. A silicone drainage tube inserted to control post-keratoplasty glaucoma. The tube has become blocked at the orbital end causing a markedly raised pressure. The graft, however, remains clear.

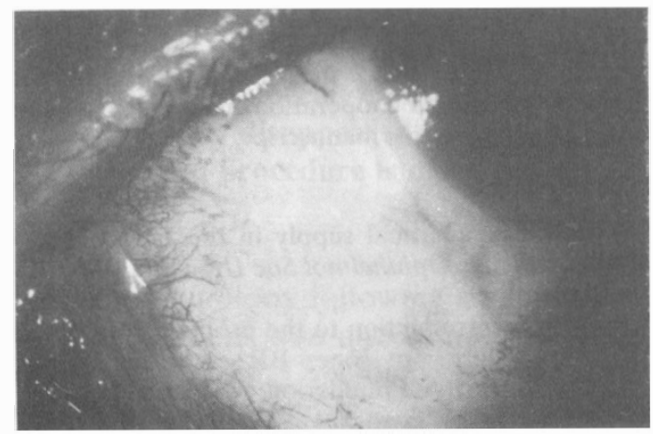

Fig. 9. The effects of tri-fluoro-thymidine toxicitynote the ischaemic conjunctiva-in a patient who had recurrent herpes keratitis in a graft and was treated with this drug.

\section{Discussion}

When considering patients for corneal transplantation, the prognosis depends not only on underlying ocular pathology and surgical technique, but also on careful post-operative follow-up and patient compliance, so that complications may be identified and treated. Patients at this hospital are advised to attend if they notice reduced vision, redness or irritation in the grafted eye, and to ensure they have an adequate supply of any prescribed treatment.

In this study of 205 consecutive cases attending the Accident and Emergency Department, over 90 per cent had demonstrable pathology and more than 50 per cent had conditions directly related to their corneal
Table III. The problems associated with decompensated grafts

\begin{tabular}{lc}
\hline \multicolumn{2}{c}{ Decompensated grafts } \\
\hline Epithelial defects & 5 \\
Painful phthisis & 4 \\
Conjunctivitis & 1 \\
Giant papilliary & \\
$\quad$ conjunctivitis & 1 \\
Decreased visual acuity & 1 \\
Perforated Descemetocoele & 1 \\
\hline
\end{tabular}

graft. In 30 per cent, there was an acute rejection episode, and such patients if diagnosed early often respond to treatment. Topical corticosteroids are the mainstay of treatment of a graft rejection and are also used routinely to suppress post-operative inflammation. Steroids have a complex action on the immune system ${ }^{5}$ as well as an anti-inflammatory action they have a direct vasoconstrictive effect which reduces vascular permeability and post-operative vascularisation. ${ }^{6,7}$ In higher doses they have an immunosuppressive effect by their inhibitory action on lymphocytes and macrophages. ${ }^{8}$ Polack $^{8}$ has shown in an experimental animal model that topical steroids can halt the endothelial phagocytosis occurring during graft rejection within 48 hours of administration.

Our study does not follow all corneal grafts performed at Moorfields but does, nevertheless, suggest that there may be a causal relationship between steroid withdrawal and development of graft rejection, and both the surgeon and patient should be alert to this risk.

Although steroids are effective in aborting rejection episodes, no recovery of damaged endothelial cells occurs, and the longer a rejection episode lasts, the greater the likelihood of graft oedema from endothelial dysfunction. Although we could not demonstrate statistical significance, those patients who presented early tended to respond more rapidly to treatment, whilst in those who delayed response to treatment was slow. Of the 4 patients with rejections in whom presentation was delayed for over one month, three developed corneal decompensation and one corneal vascularisation.

We found no correlation between the interval between surgery and the onset of graft 
rejection or graft related problems. Alldredge $^{9}$ in his retrospective study of $\mathbf{1 4 0}$ patients who had corneal graft surgery found 45 patients with graft rejections. Over 90 per cent of these rejection episodes were seen within 2 years of surgery. In our study, 57 per cent of cases occurred within 2 years of surgery and 27 per cent occurred at least 5 years after surgery. Although we were looking at a different population of patients, this illustrates the need for long term follow up of such patients.

Other graft related problems also require prompt treatment. Problems, such as broken or loose nylon sutures, represented 10 per cent of visits. If neglected, this can provide a stimulus for vascularisation and, as in two of our patients, lead to a rejection episode, or provide a nidus for infection leading to corneal abscess formation. Early treatment can prevent these problems. The sutures should be removed, if necessary in the operating theatre with facilities to resuture the graft should the need arise. The authors suggest routine prophylactic topical antibiotic and steroid cover after such a procedure since both infection and rejection may follow suture removal. ${ }^{10}$

Recurrence of herpetic eye disease may also compromise the graft integrity and may occur many years after surgery. Bacterial infection is a serious, but treatable complication which may result in extensive damage not only to the cornea but also to other ocular structures. Early treatment is of paramount importance.

One-third of the patients had disorders not directly related to graft surgery and in few, was there any immediate threat to the graft. In 10 per cent there was no demonstrable pathology. We feel, however, that it is important not to discourage such patients from attending on future occasions.

The group of patients with long standing decompensated grafts also develop complications and need long term care. In all 13 of our patients there was a genuine reason for presentation, and we were able to provide symptomatic relief for all of them, one of whom required surgery for a perforated Descemetocoele.

This study suggests that improved patient education and increased family practitioner awareness might lead to earlier presentation of corneal graft patients who develop problems. By treating complications earlier, an improvement in graft survival should be expected. We were particularly concerned that the delay in presentation seen in some patients had led to irreversible corneal damage. In a few instances, no abnormality was found but we feel that it is as important to be able to exclude pathology as it is to make a concrete diagnosis both to reassure patients, and to avoid discouraging them from attending on future occasions.

Centres performing corneal graft surgery should have the appropriate back-up facilities for assessment of patients who present with acute problems.

We would like to thank the casualty registrars and nursing staff for their cooperation and Miss Sarah Carr for preparation of this manuscript.

\section{References}

${ }^{1}$ Bradley BA: Corneal supply in the United Kingdom. Trans Ophthalmol Soc UK 1986, 105: 397 . 400.

2 Jones BR: Introduction to the problems of corneal graft failure. In: Jones BR ed. Corneal graft failure. CIBA Foundation Symposium No 15. Amsterdam: Associated Scientific Publishers, Amsterdam, 1973, 1-3.

${ }^{3}$ Lindstrom RL: Advances in corneal transplantation. New Eng J Med 1986, 315: 57-9.

${ }^{4}$ Khodadoust AA: The allograft rejection reaction: The leading cause of failure of clinical corneal graft failure. In: Jones BR ed. Corneal graft failure. CIBA Foundation Symposium No 15. Amsterdam: Associated Scientific Publishers, Amsterdam, 1973, 151-64.

${ }^{5}$ Claman HN: How corticosteroids work. J Allergy Clin Immunol 1975, 55: 145-51.

${ }^{6}$ Greeson TP, Lewan NE, Freedman RI, Woon H Wong: Corticosteroid-induced vasoconstriction studied by Xenon 133-clearance. J Invest Dermatol 1973, 61: 242-4.

${ }^{7}$ Germuth FG, Valdes AJ, Senterfitt LB, Pollack AD: A unique influence of cortisone on the transit of specific macromolecules across vascular walls in immune complex disease. Johns Hopkins Med J 1968, 122: 137-53.

8 Polack FM: Lymphocyte destruction during corneal homograft resection. Arch Ophthalmol 1973, 89: 413-6.

${ }^{9}$ Alldredge $\mathrm{OC}$ and Krachmer JH: Clinical types of corneal transplant rejection. Arch Ophthalmol 1981, 99: 599-604.

${ }^{10}$ Casey TA and Mayer DJ: Corneal grafting. W B Sanders Co; London, 1984, 304. 